\title{
Comment on the article by Bindra $A$ et al.: Is the modified Mallampati test performed in supine position a reliable predictor of difficult tracheal intubation?
}

\author{
Milan Adamus
}

Received: 6 July 2010/ Accepted: 4 August 2010/Published online: 5 November 2010

(C) Japanese Society of Anesthesiologists 2010

To the Editor:

With great interest, I read the article by Bindra et al. [1] about the modified Mallampati test performed in the supine position for prediction of difficult tracheal intubation. To judge the situation more precisely, they recommend examination of Mallampati test in both sitting and supine positions for those airways being assigned a higher grade in the sitting position.

Unfortunately, the data are incorrect in both the text and Table 2 in the paper. If we assume that the numbers of cases in Table 1 are correct, then in Table 2, the values for false positives (FP) and false negatives (FN) are wrong for both MMT-sitting and MMT-supine groups. In Table 2, FP should be 17 (and not 11) and FN should be 11 (and not 17) for the MMT-sitting group. Similarly, for the MMT-supine group, FP should be 42 (and not 5), and FN should be 5 (and not 42). These input data evidently give completely different results when Fisher's exact test is used for calculations. For MMT-sitting examination, the correct sensitivity, specificity, positive predictive value, and negative predictive value are $31,84,23$, and $89 \%$, respectively. For MMT-supine examination, the respective values are 69, 61, 21 , and $93 \%$.

Furthermore, the total number of patients mentioned in the results of the study is wrong. Although the authors studied 123 patients, they state that the test performed in the supine position was FP in 5 of 124 patients compared

An answer to this letter to the editor is available at doi:10.1007/ s00540-010-1040-0.

\section{Adamus ( $\square)$}

Department of Anesthesiology and Resuscitation,

University Hospital of Olomouc, I. P. Pavlova 6,

775-20 Olomouc, Czech Republic

e-mail: milan.adamus@seznam.cz
Table 2 Original Table 2 from the paper by Bindra et al. [1]. Statistical terms used for modified Mallampati test (MMT) performed in sitting and supine positions as predicting tests for difficult laryngoscopy (number or \%)

\begin{tabular}{lrrrrllll}
\hline Test & TP & FP & TN & FN & $\begin{array}{l}\text { Se } \\
(\%)\end{array}$ & $\begin{array}{l}\text { Sp } \\
(\%)\end{array}$ & $\begin{array}{l}\text { PPV } \\
(\%)\end{array}$ & $\begin{array}{l}\text { NPV } \\
(\%)\end{array}$ \\
\hline MMT-sitting & 5 & 11 & 90 & 17 & 23 & 98 & 31 & 84 \\
MMT-supine & 11 & 5 & 65 & 42 & 21 & 93 & 69 & 79 \\
\hline
\end{tabular}

$M M T$ modified Mallampati test, $T P$ true positive, $F P$ false positive, $T N$ true negative, $F N$ false negative, $S e$ sensitivity, $S p$ specificity, $P P V$ positive predictive value, $N P V$ negative predictive value

Table 2 Correct Table 2

\begin{tabular}{lrrrrrrrr}
\hline Test & TP & FP & TN & FN & $\begin{array}{l}\text { Se } \\
(\%)\end{array}$ & $\begin{array}{l}\text { Sp } \\
(\%)\end{array}$ & $\begin{array}{l}\text { PPV } \\
(\%)\end{array}$ & $\begin{array}{l}\text { NPV } \\
(\%)\end{array}$ \\
\hline MMT-sitting & 5 & 17 & 90 & 11 & 31 & 84 & 23 & 89 \\
MMT-supine & 11 & 42 & 65 & 5 & 69 & 61 & 21 & 93 \\
\hline
\end{tabular}

with 11 of 124 patients in the sitting position. The correct numbers are $42 \mathrm{FP}$ of 123 patients for the supine examination, and $17 \mathrm{FP}$ of 123 patients in the sitting group.

\section{Reference}

1. Bindra A, Prabhakar H, Singh GP, Ali Z, Singhal V. Is the modified Mallampati test performed in supine position a reliable predictor of difficult tracheal intubation? J Anesth. 2010;24:482-5. 